\title{
DEVELOPING AN OPERATION STRATEGY FOR A HYBRID DIESEL- WIND-PHOTOVOLTAIC SYSTEM USED TO POWER AN AUTONOMOUS AND REMOTE FISHING POND
}

\begin{abstract}
Florin NENCIU, Testing department, INMA Bucharest - National Institute for Research-Development of Machines and Installations designed for Agriculture and Food Industry, Ion Ionescu de la Brad 6 Boulevard, Bucharest, Romania, florin.nenciu2000@yahoo.com (corresponding author)

Iulian VOICEA, Testing department, INMA Bucharest - National Institute for Research-Development of Machines and Installations designed for Agriculture and Food Industry, Ion Ionescu de la Brad 6 Boulevard, Bucharest, Romania, voicea_iulian@yahoo.com Valentin VLADUT, General Manager, INMA Bucharest - National Institute for Research-Development of Machines and Installations designed for Agriculture and Food Industry, Ion Ionescu de la Brad 6 Boulevard, Bucharest, Romania, valentin_vladut@yahoo.com

The off-grid hybrid energy systems have become a viable sustainable alternative for supplying with energy isolated autonomous farms, being more reliable options, since they have more than one electricity generation sources. This article addresses the challenges related to the configuration of a hybrid energy system composed of a wind turbine, photovoltaic panels, a diesel generator and rechargeable battery storage, which is associated with an autonomous off grid fishing pond. The first step in designing predictive control was to define consumers, their particularities in operation, and their energy demand model, then to estimate the real potential of producing renewable energy depending on the location and to create consumption models that maximize the use of power from renewable resources.

A consumption management strategy has been developed for an autonomous and automatic fish pond management system, identifying optimal energy requirements for the proper operation of the needed equipment. In order to operate as much as possible using the regenerative energy resources, a prioritizing energy consumption pyramid was designed and tested and a more efficient technique of allocating energy within 24 hours of operation was defined.
\end{abstract}

Keywords: renewable energy, autonomous fishing pond, hybrid power supply

\section{INTRODUCTION}

Modern fish farming is a fast-growing industry, oriented towards intensive agricultural practices that aim to maximize yields from available terrestrial and aquatic resources, using various innovative means (Helleik, 2016). Compared to other food production chains, aquaculture is considered a more sustainable and environmentally-friendly agricultural branch for producing highly nutritious food (Troell, 2017), since fish is a source of high-quality proteins and other essential elements for human health (Asumadu-Sarkodie, 2016).

The latest approaches to sustainable agriculture require more attention to the way farming activities affect the environment, because intensive growth practices have raised over time concerns and criticism for various environmental impacts (Miljodirektoratet, 2012). One of the main concerns in case of high-performance fishing farms is related to the high levels of energy consumed in the operation and management processes, and for the deficiencies in wastewater treatment (Bocklisch, 2016).

In order to improve the identified environmental problems, can choose for the solution of moving the fishing farms out from the vulnerable areas or adopting closed systems. Many of the pollution problems generated by the fisheries sector can be solved by creating closed systems, but their energy consumption is generally considerably higher.

Providing power from renewable sources to fishing farms brings several benefits to the environment and may generate a high level of autonomy, especially in the case of isolated or large capacity pond.

The main challenge experienced by project managers when designing renewable energy generation systems is the proper sizing of components for different sites, considering the different climatic specificities, dimensions and technologies (Podder, 2015).

The ecological and economic sustainability of renewable energy systems could vary depending on geographical conditions and the availability of green energy subsidies (Gan, 2015). Adequate planning of energy supply from renewable energy systems that have a low impact on the environment would be an important step towards achieving sustainable development of aquaculture (Arikan, 2019).

Copyright (C) 2021 The Authors. Published by Vytautas Magnus University. This is an open-access article distributed under the terms of the Creative Commons Attribution License (CC BY 4.0), which permits unrestricted use, distribution, and reproduction in any medium, provided the original author and source are credited. 
An estimation of the energy demand for a fishing farm can be obtained by considering the intensity of the operations, the degree of mechanization, the type or means of production, and the quality and quantity of feed inputs (Troell, 2017).

Improvement in a hybrid power system performance can be achieved by predicting reliable outputs that can integrate renewable energy technologies into conventional power generation. Sizing hybrid power generation systems is extensively investigated in the literature, using different approaches.

Significant improvements can be made with regards to energy reductions for the farming processes, by installing more economical, more efficient equipment and by producing local energy using renewable sources. Hybrid energy systems meet the electric power demand in a reliable and continuous manner, producing energy using multiple sources. The aim of a hybrid energy system is to supply the load uninterruptedly, and to ensure a high level of autonomy (Diab, 2016).

The concept of sustainability demands a balance between energy availability, accessibility, economic viability, environmental impacts and social interactions (Saheb-Koussa, 2011; Amer, 2013). Energy forecasting is a vital input required in the conceptual framework of sustainable energy policies of every farm. Predictive strategies and long-term control strategies are often difficult to achieve, since the problem is nonlinear, the sources of renewable energy and energy demand are to some extent unpredictable and multivariable (Nottona, 2011; Costa et al, 2018). Difficulties have been identified in the elaboration of strategies based on predictive control (Zhu, 2015; Sachs et al, 2016; Maouedja, 2014). In their study, Sarkodie et all (2016) proposed a predictive control model that minimizes the cost, having as objectives maximizing the use of power from solar and wind renewable resources, and by storing as much as possible power in excess. Gan (2015) introduces a model that has been developed as a graphical user interface, and can predict the optimum configuration of a hybrid system, paying special attention to the configuration of the battery system. Combining renewable energy sources with diesel generation, they obtained a reliable electricity supply with reduced battery storage, or diesel requirements. Regarding the sizing efficiency depending on the seasonal climate, a more advantageous option proved to be the adding to the system of a fossil fuel-based generation, rather than excessively increasing the photovoltaic or wind potential, in order to cope to the difficult months (Celik, 2003).

One of the recommended applications of the hybrid systems is for remote locations, where it is fundamental to combine, integrate, harmonize and coordinate electricity production from different generators. The goal is to design the system in such a way as to supply the minimum energy requirement, without oversizing the system. The first concern related to renewable energy sources is associated to the fact that they are usually available intermittently. Photovoltaic generation of electric power is dependent of the season and can only produce energy during the daytime. A wind turbine will only work when the wind reaches a certain minimum level, and there may be long periods when there is no energy produced for some geographic areas. The solution for storing excess energy and subsequent use is to use battery banks, but this requires a careful management, given the high cost of investment (Garcia, 2013).

Diesel power generator is an essential element for small scale electricity generation systems, but it has to be used only for short time intervals, given the high operating costs. Hybrid systems have been identified as economically beneficial solutions, especially for locations where there are significant variations across seasons in terms of wind, temperature or solar radiation (Bhattacharjee, 2014; Bocklisch, 2016). Suresh Kumar (2014) noted that most of the hybrid energy costs tend to be higher, compared to the option of connecting to the national electricity grid, therefore the solution seems to be more viable for autonomous systems located in remote areas. Electric energy generation using the hybrid photovoltaic - wind turbines for Bucharest may present pronounced monthly variations, depending on several variables such as solar irradiation, temperature value, air density, pressure, and wind speed. This is the reason the proposed system was designed with a diesel generator that can produce electricity in case of emergency.

\section{MATERIALS AND METHODS}

The present study aims to design an operating strategy for a hybrid energy system, used to power an autonomous fish farming system. It was considered the case of a pond populated with juvenile fish, thus the operating conditions are more sensitive, and the design of the energy supply has a hazardous potential.

We proposed the use of a hybrid power supply system composed of a photovoltaic array, a wind turbine, a diesel generator, and a lithium ion battery bank. The renewable photovoltaic-wind components have to supply the needed energy, while the periods with low production are being covered by the rechargeable battery system. The diesel generator is used for emergencies only, or for special situations when batteries cannot cope with consumption, or for a temporary unexpected increase in energy demand. The objective was to maximize the use of power from renewable resources, that were corelated to the local weather conditions, minimizing as much as possible the use of fossil fuel power. In addition to an improved impact on the environment, the aim was to create a design that allows prolonging the life of the rechargeable batteries, considering that extending their lifetime is crucial for the economic viability and for energy security of the system.

The analyzed pond is built of reinforced concrete, has the size of 7 meters long, 3.5 meters wide and 2 meters deep, being intended for raising juvenile fish (Fig 1). At the time when experiments were performed, the pond was not populated with fish. The hybrid power supply system is composed of a number of 8 photovoltaic panels with a maximum power Pmax $=310 \mathrm{~W}$ each (and another 7 panels serving the main pond, which were not considered in the analysis), and a wind turbine with the power Pmax $=600 \mathrm{~W}$ (Fig 3). The consumers that were powered with electrical energy, associated with the pond were: the aerator that provides oxygen to the fish (Fig 4), UV-C sterilizer (Fig 5), an organic mechanical filter 
for ponds (fig 6), a water recirculation pump, a skimmer for collecting waste from the water surface, sensors, PLC, data logger (Fig 7), a display and data processing system, an automatic fish feeding equipment, the lighting system and the surveillance system.

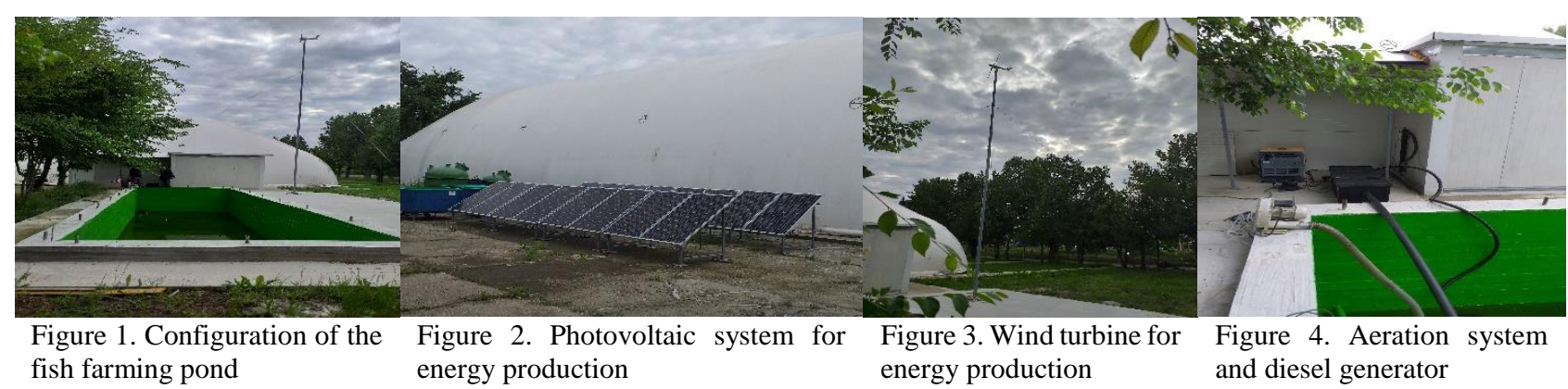

The unused energy, produced from renewable sources is stored by four solar rechargeable batteries - $12 \mathrm{~V} / 250 \mathrm{Ah}$, (Fig. 8). In order for the hybrid system to be able to make the most efficient use of the different renewable resources, it must ensure a stable and reliable power generation, and avoid the diesel generator coming into operation. Solar energy system cannot provide a continuous source of energy, especially during winter, while the wind system cannot satisfy constant load to the turbine, due to different magnitude of wind speed. Therefore, a customization of the hybrid system must be made depending on the location and the operating features of the energy consumers.

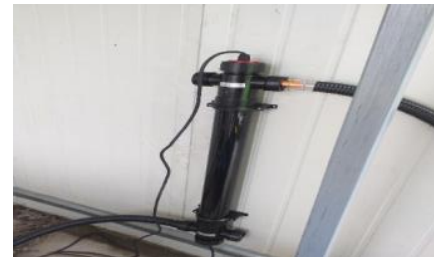

Figure. 5. UV-C sterilizer

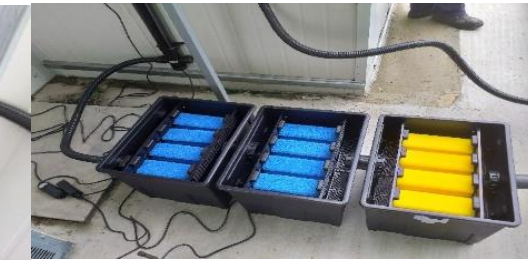

Figure. 6. Mechanical filter for ponds

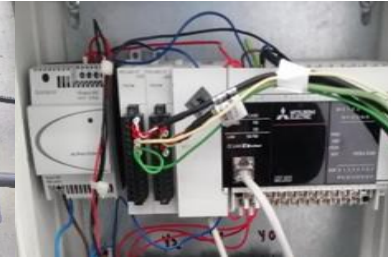

Figure 7. Automation and control system

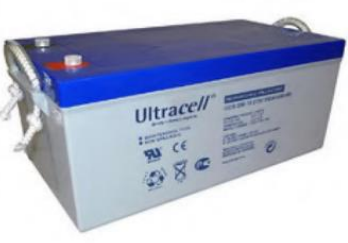

Figure 8. Energy storage using rechargeable batteries

\section{RESULTS AND DISCUSSION}

The control strategy for a hybrid system that powers an autonomous fishing pond is necessary to manage the energy exchange between energy sources and the required load, due to the uncertain nature of renewable generation and load demand. In stand-alone operating mode, if the power generated is not enough to cover the load, the batteries are discharged to provide sufficient power to the system. If the charging demand exceeds the maximum power supply generated by the battery system leading to complete discharge, the lack of power is supplied from the diesel generator.

Identifying the optimal energy requirements for the proper operation of the needed equipment

In order to obtain the juvenile fishing farm management system autonomy, an operation strategy has to be created for the equipment, so that the most important power consumers to be prioritized.

All devices used have been selected to have a low energy consumption, being adapted for the dimensions and constructive characteristics of the fishing pond. In the first phase, the real consumption of each device / equipment was recorded, and then was decided the number of hours per day they have to work, avoiding as much as possible the excessive operation.

Oxygen demand in the fishing pond has to include the respiration rate of the fish, the respiration rate of other aquatic organisms thar are found in the water (such as phytoplankton) and the respiration rate of sediments (organic matter in the process of decomposition). In the oxygenation process using aeration equipment, the efficiency of oxygen transfer from air to water depends on a number of factors such as: bubble size, air flow pumped into water, aeration disc surface, pumping depth, etc. Given that young fish consume more oxygen than adult fish (calculated per kg with about $30 \%$ more), and considering that the aeration system must be dimensioned so as to take over the variation due to the heat and stress of young fish, have been selected an equipment with an energy consumption of $30 \mathrm{Wh}$, operating continuously.

The water purification system consists of a water recirculation pump, a mechanical filter and a UV-C sterilizer. In order not to contaminate the filter with leaves brought by the wind, a skimmer has been installed, having the role of taking over the vegetation from the water surface. The purification system can pass all the water from the pond through the filter in an interval of about 4 hours, however the chosen economic operation interval was for 3 hours daily.

It was decided to use an economic monitoring and control system, which needs only $10 \mathrm{Wh}$ continuous energy demand, and another extra $120 \mathrm{~W}$ for two hours per day. The feeding system has been programed to operate using a total energy of $28 \mathrm{Wh}$ per day. Table 1 summarizes the daily operation approach (for 24 hours) in terms of energy consumption, evaluated in an economical way, flattening the consumption peaks as much as possible. The green color highlights the required power and the operating hours of the equipment. 


\begin{tabular}{|c|c|c|c|c|c|c|c|c|c|c|c|c|c|c|c|c|c|c|c|c|c|c|c|c|c|}
\hline \multirow[b]{2}{*}{ System } & \multirow[b]{2}{*}{ Equipment } & \multirow{2}{*}{\multicolumn{2}{|c|}{$\begin{array}{l}\text { Equipment nominal } \\
\text { power }\end{array}$}} & \multicolumn{22}{|c|}{ Operation hours in one day $(24 \mathrm{~h})$} \\
\hline & & & & 1 & 2 & \begin{tabular}{l|l|l|l|}
4 & 5
\end{tabular} & \multicolumn{2}{|l|}{$5 \mid 6$} & & & \begin{tabular}{l|l}
11 & 12
\end{tabular} & \multirow[t]{2}{*}{13} & \multirow[t]{2}{*}{\begin{tabular}{l|l}
14 & 1
\end{tabular}} & & & \multirow{2}{*}{\begin{tabular}{|l|l}
18 & 19 \\
130 & \\
\end{tabular}} & \multirow[t]{2}{*}{920} & \multirow[t]{2}{*}{21} & \multirow[t]{2}{*}{122} & \multirow{2}{*}{\multicolumn{2}{|c|}{\begin{tabular}{|l|l|}
23 & 2 \\
23
\end{tabular}}} & \multicolumn{2}{|c|}{$\begin{array}{l}\text { Total daily energy } \\
\text { consumption per } \\
\text { equipment }\end{array}$} \\
\hline $\begin{array}{l}\text { Water filtration, } \\
\text { sanitation and }\end{array}$ & \begin{tabular}{|l|} 
Water recirculation pump \\
Organic mechanical filter for ponds \\
\end{tabular} & 130 & w & & & & & 130 & & & & & 130 & & & 16 & & & & & & & & 390 & Wh \\
\hline recirculation system & Skimmer & 70 & w & & & & 70 & if & & & & & & 70 & 70 & & & & 70 & & & & & 280 & \\
\hline in the pond & UV-C sterilizer & 75 & w & & & & & 75 & 5 & & & & 75 & & & & & 75 & & & & & & 225 & Wh \\
\hline $\begin{array}{l}\text { Pond water } \\
\text { aeration system }\end{array}$ & Aerator for fish ponds & 30 & w & \begin{tabular}{|l|l}
30 & 30 \\
\end{tabular} & 030 & $\begin{array}{ll}30 & 30 \\
\end{array}$ & 30 & & & 30 & 30 & 30 & & 30 & $30 \mid 30$ & 30 30 & 30 & & & $30 \quad 30$ & \begin{tabular}{l|l|}
30 & 30 \\
\end{tabular} & & 30 & 570 & Wh \\
\hline Monitoring and & Sensors, PLC, data logger & 10 & W & \begin{tabular}{|l|l|}
10 & 10 \\
\end{tabular} & 010 & \begin{tabular}{l|l}
10 & 10 \\
\end{tabular} & $10 \quad 10$ & $\begin{array}{ll}0 & 10 \\
\end{array}$ & 10 & 10 & 10 & 10 & 10 & 10 & \begin{tabular}{|l|l|}
10 & 10 \\
\end{tabular} & $10 \quad 10$ & 10 & 10 & \begin{tabular}{l|l}
10 & 1 \\
\end{tabular} & $10 \quad 10$ & \begin{tabular}{l|l|}
10 & 10 \\
\end{tabular} & $\begin{array}{ll}0 & 10 \\
\end{array}$ & 10 & 240 & \\
\hline control system & Display and data processing system & 120 & W & & & & & & & & 120 & 120 & & & & & & & & & & & & 240 & \\
\hline $\begin{array}{l}\text { Automatic fish } \\
\text { feeding system }\end{array}$ & Automatic fish feeding eaquiment & 7 & w & & & & & & 1 & 1 & & & & 7 & & & & & 7 & & & 7 & 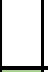 & 28 & Wh \\
\hline Auxiliary systems & Lighting system & 20 & W & \begin{tabular}{|l|l|}
20 & 20 \\
\end{tabular} & 020 & 2020 & $\begin{array}{ll}20 \quad 20 \\
\end{array}$ & 0 & & & & & & & & & & & & & \begin{tabular}{ll|}
$20 \quad 20$ \\
\end{tabular} & 20 & 20 & 200 & \\
\hline $\begin{array}{l}\text { (lighting and } \\
\text { surveillance) }\end{array}$ & Surveillance system & 20 & w & 2020 & 020 & 2020 & $20 \quad 20$ & 0 & & 20 & 20 & 20 & 20 & 20 & 2020 & $20 \quad 20$ & 20 & 20 & & & $20 \quad 20$ & 020 & 20 & 480 & Wh \\
\hline & urly energy consumed by the install & & & 80 & 80 & $\begin{array}{l}8080 \\
80\end{array}$ & $80 \quad 120$ & 235 & 67 & 60 & 180 & 180 & 235 & 137 & \begin{tabular}{|l|l|}
130 & 60 \\
\end{tabular} & 060 & 602 & 235 & 10760 & 5080 & $\begin{array}{ll}80 & 80 \\
\end{array}$ & 87 & 80 & 2653 & Wh \\
\hline
\end{tabular}

Can be observed the power needs for each operating system, working within the fishing pond (consisting of one or more devices/equipment). Starting from the nominal power and the number of operating hours, can calculate and model the daily energy consumption, so that the system responds best to the opportunities and established constraints.

The largest power consumers were chosen to operate during the daytime, when the photovoltaic panels can provide energy. The electricity produced will no longer be directed to the batteries, being oriented through a by-pass directly to consumers. In this way the batteries can store only the surplus of produced energy, and their degradation process will be smaller. Although power consumers need to operate as much as possible during the day, some of them (such as water recirculation, filtration and sterilization equipment) are interdependent and need to be turned on at the same time.

The table indicates that the minimum daily energy designed to be supplied by the hybrid system should not be less than $2653 \mathrm{Wh}$, for 24 hours. A significant illustration is shown in Fig. 9., that highlights peak energy consumption for 24 hours. In the case of autonomous systems, it is very important to identify the optimal energy allocation to equipment, according to the importance. The hierarchy was analyzed, the results being highlighted in Fig. 10.

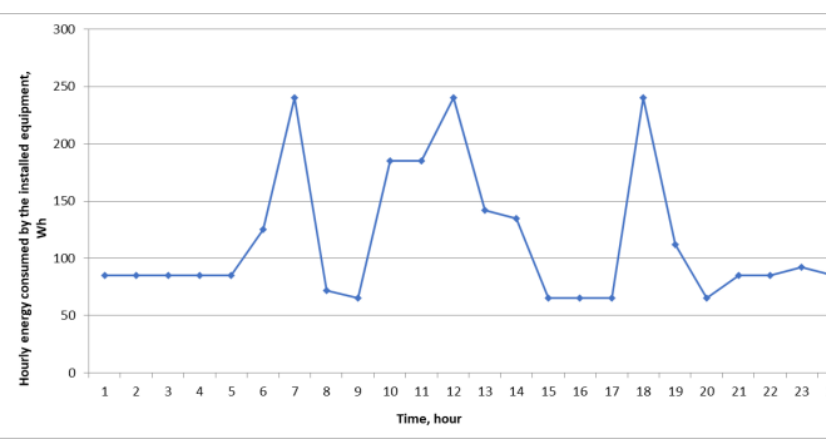

Figure 9. Determining the maximum power that has to be covered by the hybrid photovoltaic-wind system

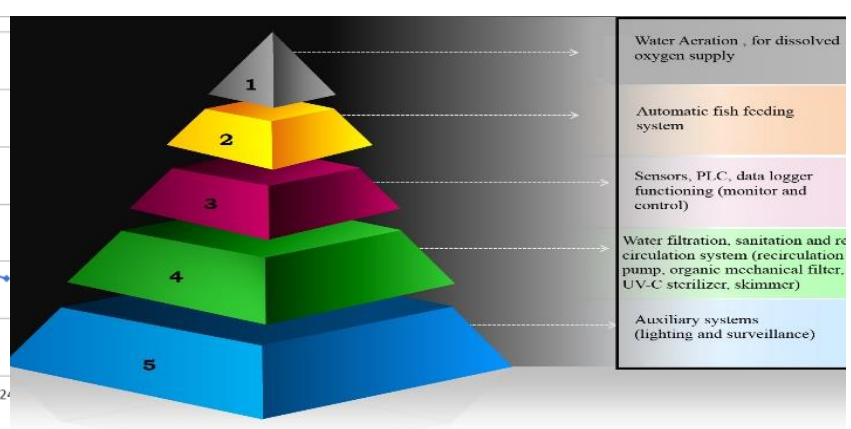

Figure 10. Building a prioritizing pyramid for the operation of the equipment associated to the pond

It can be seen that the minimum daily energy consumption designed to be supplied by the hybrid system must be $2653 \mathrm{Wh}$, for 24 hours. If the renewable energy sources (photovoltaic and wind) will not be able to cover the necessary, then the power will be taken from the energy stored during periods of overproduction from the rechargeable batteries. When the batteries give all the available energy, then the diesel generator will start operating.

The pyramid that ranks according to importance, the supply of electricity, have been divided into 5 main functions. The most important function is aeration, because without an optimal amount of oxygen the fish could die in a short time (depending on the species), and in second place is the automatic feeding system. Being designed as an automatic system, the monitoring of the basin is considered as the third most important function, because depending on the recorded values, operation commands are transmitted to the other systems (filtration, water recirculation, sterilization, etc.). Auxiliary systems such as lighting and surveillance system are of the least importance and have been programmed to shut down first if the system automatically identifies a problem in power generation for the next few hours.

Only the photovoltaic-wind system has been calculated, because renewable energy should cover as much as possible of the operating needs, while the diesel generator should take over the emergencies and temporary deficits.

The solar radiation, depending on the specific geographical locations, follows the normal logarithmic PDF, with the mean $\lambda$ and the standard deviation $\sigma$ of the natural logarithm of the variable as follows:

,where $\mathrm{G}$ is the solar radiation.

$$
f_{G}(G)=\frac{1}{G \cdot \sigma \cdot \sqrt{2 \pi}} \cdot \exp \left\{\frac{-(\ln G-\lambda)^{2}}{2 \cdot \sigma^{2}}\right\}, \text { for } G>0
$$


The output power of the photovoltaic panel depends not only on solar radiation, but also on the ambient temperature, wind speed and the performance of the module itself. The hourly output power of the photovoltaic system can be calculated by the equation:

$$
P_{P V}=\eta_{P V, S T C} \cdot\left[1+\frac{\mu}{\eta_{P V, S T C}} \cdot\left(T_{a}-T_{S T C}\right)+\frac{9.5 \cdot \mu \cdot(N O C T-20) \cdot\left(1-\eta_{P V, S T C}\right)}{800 \cdot \eta_{P V, S T C} \cdot(5.7+3.8 \cdot v)} \cdot G_{g}\right] \cdot A_{P V} \cdot G_{g}
$$

where $\mathrm{P}_{\mathrm{PV}}$ is the hourly output power of the photovoltaic system $(\mathrm{W}), \eta_{P V, S T C}$ is the efficiency of the photovoltaic module under standard test conditions (STC) (\%), $\mu$ is the temperature coefficient of the output power $\left(\% /{ }^{\circ} \mathrm{C}\right)$, Ta is the ambient temperature $\left({ }^{\circ} \mathrm{C}\right)$, TSTC is the temperature of the standard test conditions $\left(25^{\circ} \mathrm{C}\right), v$ is the wind speed $(\mathrm{m} / \mathrm{s})$, NOCT is the nominal operating temperature of the photovoltaic cell $\left({ }^{\circ} \mathrm{C}\right)$, Apv is the grid area photovoltaic associated with the peak power $\left(\mathrm{m}^{2}\right)$, and $\mathrm{Gg}_{\mathrm{g}}$ is the global solar radiation on the inclined surface $\left(\mathrm{W} / \mathrm{m}^{2}\right)$.

Using the data obtained from our internal weather station and a pyranometer equipment, have been drown the monthly averages of the daily radiation level for Bucharest (Fig. 11), the annual average of the daily solar radiation produced being $56 \%$ of the maximum installed theoretical power.

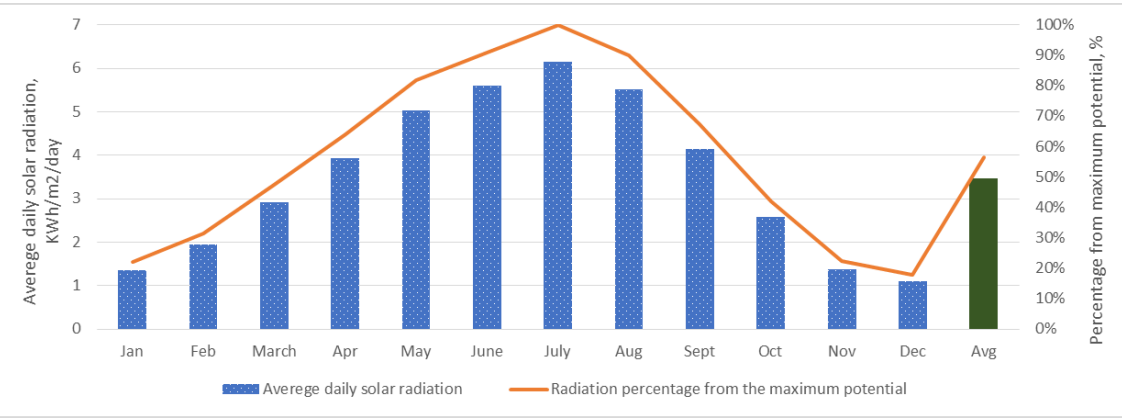

Figure 11. Monthly averages of the daily radiation levels for Bucharest, for year 2020.

Other evaluated data that influence photovoltaic energy production were: monthly average sunny hours and days for Bucharest (Figure 12), monthly average cloud cover and air humidity (Figure 13), and monthly average temperatures (Figure 14.).

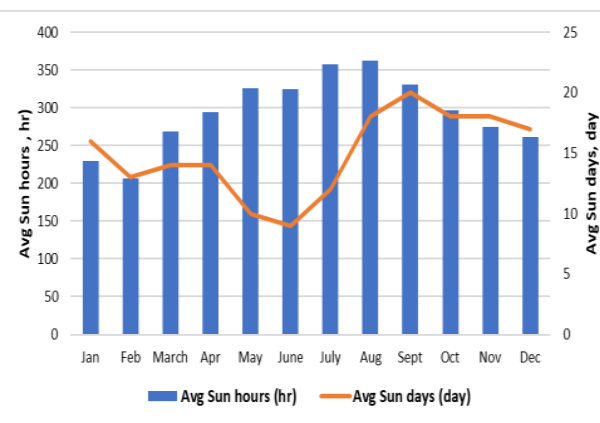

Figure. 12. Monthly average sunny hours and days for Bucharest, Romania

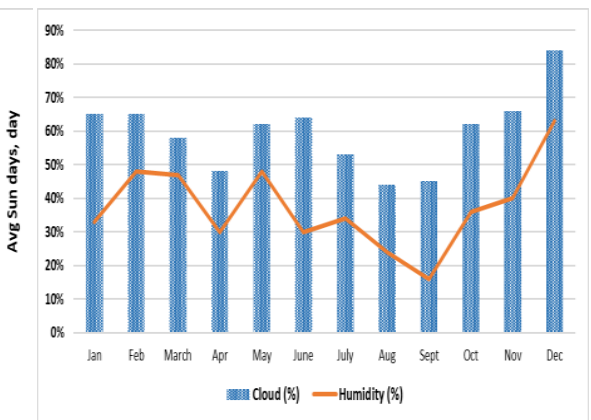

Figure. 13. Monthly average cloud cover and air humidity for Bucharest, Romania

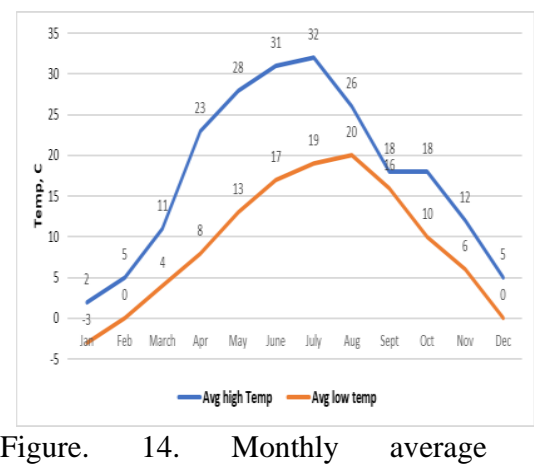

temperatures for Bucharest, Romania

Using equation (1) and the information discussed in the figures above, the photovoltaic system was dimensioned to a number of 10 panels, each having a maximum installed power of Pmax $=310 \mathrm{~W}$, and Isc $=10,226 \mathrm{~A}$. The real energy provided by the photovoltaic system daily and monthly depending of the moon, are highlighted in Fig. 15 and Fig. 16.

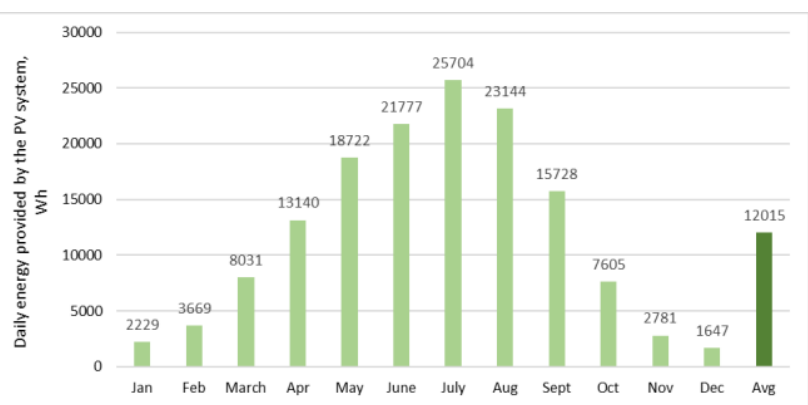

Figure. 15. Daily energy production using photovoltaic system (average for 12 months)

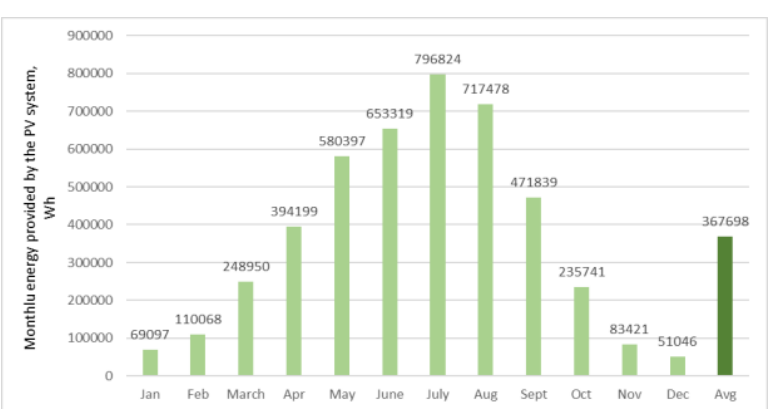

Figure. 16. Monthly energy production using photovoltaic system (for 12 months) 
The generating power of the wind turbine in a certain place is correlated with the wind speed at a certain rotor height and the wind characteristics in association with the turbine. Therefore, wind speed measured at a reference height should be converted using the logarithmic step as in equation (3).

$$
v=\mathrm{v}_{\text {ref }} \cdot \frac{\ln \left(\frac{\mathrm{h}}{\mathrm{z}_{0}}\right)}{\ln \left(\frac{\mathrm{h}_{r e f}}{\mathrm{z}_{0}}\right)}
$$

where $v_{\text {ref }}$ is the measured wind speed at the reference height $(\mathrm{m} / \mathrm{s}), \mathrm{h}$ is the actual height $(\mathrm{m})$, href is the reference height $(\mathrm{m})$, and $\mathrm{z}_{0}$ represents the surface roughness length $(\mathrm{m})$.

However, the Weibull probability distribution function is widely used to express the wind speed distribution at a certain rotor height, depending on the form factor $\mathrm{k}$ and the scale factor $\mathrm{c}(\mathrm{m} / \mathrm{s})$ as in equation (4).

$$
f_{v}(v)=\frac{k}{c} \cdot\left(\frac{v}{c}\right)^{k-1} \cdot \exp \left[-\left(\frac{v}{c}\right)^{k}\right], \text { for } 0<\mathrm{v}<\infty
$$

For the wind energy production system, we opted for a wind turbine with a working power of $600 \mathrm{~W}$. In figure 17 can be seen the variation of the monthly wind speed, recorded for year 2020. However, the operating performance of the wind turbine proved to be much lower, the average energy produced per month being in the range of $17-27 \%$ of the nominal values of the system. The average daily value recorded was $1320 \mathrm{Wh} /$ day, but it should be noted that there were days when the wind turbine did not work at all.

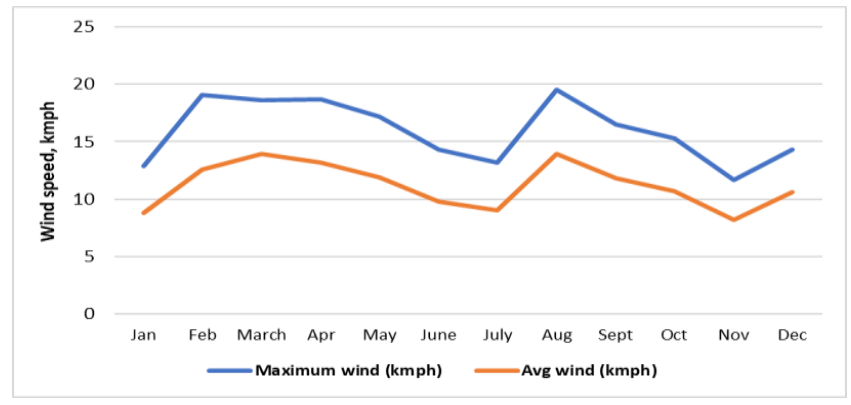

Figure 17. The variation of the monthly wind speed, for year 2020

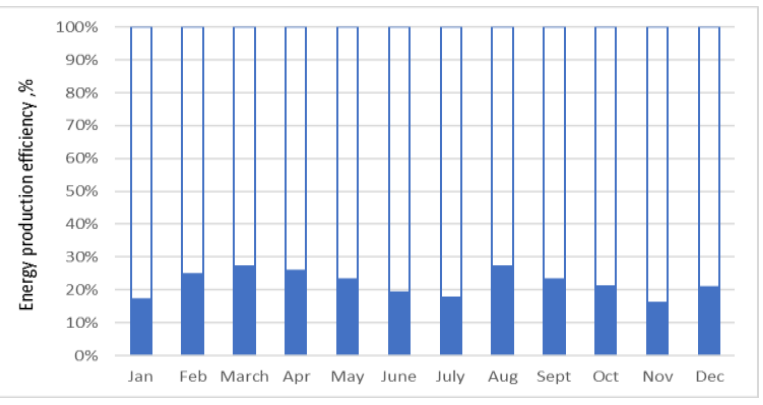

Figure 18. Energy production efficiency for the wind turbine, for the year 2020

All the extra energy generated by the wind is stored in the battery system, and is consumed during the winter, when the photovoltaic system fails to provide the minimum requirement of $2700 \mathrm{Wh}$. The diesel generator is provided as a back-up for emergencies, when management problems occur, it can generate energy for the operation of the pond equipment for 2 days.

\section{CONCLUSIONS}

This paper is part of an extensive research that aims to bring renewable energy closer to fish farming ponds, in order to better protect the environment and save energy. The proposed power generation system has proven to be able to support total energy consumption, however we identified the need to install an additional diesel back-up system that can replace renewable systems in the short periods of lack of power generated.

A consumption projection was made according to the nominal power of each consumer associated with the fish pond. Tested in real operating conditions, the assessment of energy consumption has been proven to keep energy peaks at very low values, so that the power stored in the rechargeable battery system is not exceeded. This also allowed enabling the optimal operating hours for each equipment and to frame the 24 hours consumption in the power generated by the hybrid system.

The analysis of energy production using the hybrid system, for the climatic conditions of the city of Bucharest showed that the association of a photovoltaic system with a wind generator brings important benefits to the autonomous ponds functioning. Although photovoltaic panels are more reliable in producing a constant amount of energy during the day, wind turbines allow additionally energy to be stored in batteries during periods of high wind, bringing a considerable operational surplus.

The main output of the study was determining the maximum power that has to be covered by the hybrid photovoltaic-wind system, followed by the construction of a prioritizing pyramid for the operation of the equipment associated to the pond. This creates the chance for a more efficient and reliable system management and a more secure approach.

Acknowledgements. This paper was financed by support of Romanian Ministry of Agriculture and Rural Development (MADR), Contract no. 2531/26.09.2019, project ADER 25.3.1. 


\section{REFERENCES}

1. Amer M., Namaane A., M'Sirdi M.K. 2013. Optimization of hybrid renewable energy systems (HRES) using PSO for cost reduction. Energy Procedia, Vol. 42, pp. 318-327. https://doi.org/10.1016/j.egypro.2013.11.032

2. Arikan O., İsen E., Kekezoglu B., 2019. Performance analysis of stand-alone hybrid (wind-photovoltaic) energy system. Pamukkale Univ Muh Bilim Derg, Vol. 25(5), pp. 571-576. https://doi.org/10.5505/pajes.2018.98958

3. Asumadu-Sarkodie S., Owusu P.A. 2016. The potential and economic viability of wind farms in Ghana Energy Sources. Part A: Recovery, Utilization, and Environmental Effects. Vol. 38, Issue 5, pp. 695-701. https://doi.org/10.1080/15567036.2015.1122680

4. Asumadu-Sarkodie S., Sevinc C., Jayaweera H.M.P.C., 2016. A hybrid solar photovoltaic-wind turbine-Rankine cycle for electricity generation in Turkish Republic of Northern Cyprus. Cogent Engineering, Vol. 3, ID 1180740. https://doi.org/10.1080/23311916.2016.1180740

5. Bhattacharjee S, Acharya S. 2014. PV-wind hybrid power option for a low wind topography. Energy Convers Manage; Vol. 89, pp. $942-54$. https://doi.org/10.1016/j.enconman.2014.10.065

6. Bocklisch T., Lindner J. 2016. Technical and economic investigation and comparison of photovoltaic - wind energy - hybrid systems with battery and heatstorage path. Energy Procedia, Vol. 99, pp. 350 - 359. https://doi.org/10.1016/j.egypro.2016.10.125

7. Celik AN. 2003. Techno-economic analysis of autonomous PV-wind hybrid energy systems using different sizing methods. Energy Convers Manage, Vol. 44, pp. 1951-68. https://doi.org/10.1016/S0196-8904(02)00223-6

8. Costa A. J. A. S., Valério da Costa Branco D. P. J. 2018. Predictive control model to manage power flow on a hybrid wind-photovoltaic and diesel microgeneration power plant with additional storage capacity. Special Issue: Cyber Physical Power Systems: Advanced Intelligent Technologies and Applications, IET Cyber-Phys. Syst., Theory \& Application, Vol. 3 ( 4), pp. 206-211. https://doi.org/10.1049/iet-cps.2018.5037

9. Diab F., Lan H., Zhang,L., Ali S. 2016. An environmentally friendly factory in Egypt based on hybrid photovoltaic/wind/diesel/battery syste. Journal of Cleaner Production, Vol. 112, pp. 3884-3894. https://doi.org/10.1016/j.jclepro.2015.07.008

10. Garcia P., Torreglosa J.P., Fernandez L.M. 2013. Optimal energy management system for standalone wind turbine /photovoltaic/hydrogen / battery hybrid system with supervisory control based on fuzzy logic. International Journal of Hydrogen Energy, Vol. 38, pp. $14146-14158$. https://doi.org/10.1016/j.ijhydene.2013.08.106

11. Gan L.K., Shek J.K.H., Mueller M.A. 2015. Hybrid wind-photovoltaic-diesel-battery system sizing tool development using empirical approach, life-cycle cost and performance analysis: A case study in Scotland. Energy Conversion and Management, Vol. 106, pp. 479-494. https://doi.org/10.1016/j.enconman.2015.09.029

12. Helleik L. Syse, 2016. Investigating Off-Grid Energy Solutions for the Salmon Farming Industry, Department of Mechanical and Aerospace Engineering, University of Strathclyde.

13. Maouedja R., Mammeria A., Draoua M.D., Benyouce B. 2014. Performance evaluation of hybrid Photovoltaic-Wind power systems. Energy Procedia, Vol. 50 pp. 797 - 807. https://doi.org/10.1016/j.egypro.2014.06.098

14. Nottona G., Diafb S., Stoyanovc L. 2011. Hybrid Photovoltaic/Wind Energy Systems For Remote Locations. Energy Procedia, Vol. 6, pp. 666-677. https://doi.org/10.1016/j.egypro.2011.05.076

15. Podder S., Khan R.S., Mohon S.A.A. 2015. The Technical and Economic Study of Solar-Wind Hybrid Energy System in Coastal Area of Chittagong, Bangladesh. Journal of Renewable Energy, Vol. 2015, pp. 1-10. https://doi.org/10.1155/2015/482543

16. Saheb-Koussa D., Koussa M., Belhamela M., Haddadi M. 2011. Economic and environmental analysis for grid-connected hybrid photovoltaic-wind power system in the arid region. Energy Procedia, Vol. 6, pp. 361-370. https://doi.org/10.1016/j.egypro.2011.05.042

17. Sachs J., Sawodny O. 2016. A two-stage model predictive control strategy for economic diesel-PV-battery island microgrid operation in rural areas. IEEE Transactions on Sustainable Energy, Vol.7, (3), pp. 903-913. https://doi.org/10.1109/TSTE.2015.2509031

18. Suresh Kumar U, Manoharan PS. 2014. Economic analysis of hybrid power systems (PV/diesel) in different climatic zones of Tamil Nadu. Energy Convers Manage, Vol. 80, pp. 469-76. https://doi.org/10.1016/j.enconman.2014.01.046

19. Troell M., Tyedmers P., Kautsky N., Ronnback P. 2017. Aquaculture and Energy Use. Encyclopedia of Energy, Vol. 1. pp. 97-107. https://doi.org/10.1016/B0-12-176480-X/00205-9

20. Zhu B., Tazvinga H., Xia X. Switched model predictive control for energy dispatching of a photovoltaic-diesel-battery hybrid power system. IEEE Transactions on Control Systems Technology, Vol. 23(3), pp. 1229-1236. https://doi.org/10.1109/TCST.2014.2361800 